\title{
Cases series: ultrasound-guided supraclavicular block in 105 patients
}

\author{
Dae Geun Jeon, and Won Il Kim \\ Department of Anesthesiology and Pain Medicine, College of Medicine, Dankook University, Cheonan, Korea
}

Background: Multiple needle attempts to gain a muscle twitch or a paresthesia for a classical supraclavicular brachial plexus block can increase the risks of nerve damage or pain. The aims of this study were to obtain reliable clinical data on ultrasound-guided supraclavicular blocks, demonstrate the higher success rate and fewer complications, and design an injection method for patients whose brachial plexus can not be located.

Methods: 105 patients received an ultrasound-guided supraclavicular block. $40 \mathrm{ml}$ of 1\% mepivacaine was injected without a muscle twitch or paresthesia. The groups were divided into two groups - Group A ( $\mathrm{n}=92$, patients who had visible brachial plexus) and Group B ( $\mathrm{n}=13$, patients whose brachial plexus can't be located). After the blocks, the clinical characteristics such as the success rate, the time to onset, the extent of the sensory block, and occurrence of complications were evaluated.

Results: The Success rate of Group A (98.9\%) was higher than that of Group B (84.6\%) $(\mathrm{P}<0.05)$. The overall success rate was $97.1 \%$. All patients could be operated on under sedation. The time to onset of Group A (12.6 $\pm 4.4 \mathrm{~min})$ was shorter than that in Group B $(23.1 \pm 5.1 \mathrm{~min})(\mathrm{P}<0.05)$. The overall time to onset was $13.8 \pm 5.5 \mathrm{~min}$. There were no serious complications such as pneumothorax.

Conclusions: An ultrasound-guided supraclavicular block is very effective in even patients whose brachial plexus can not be located. (Korean J Anesthesiol 2010; 58: 267-271)

Key Words: Brachial plexus block, Ultrasound-guided supraclavicular block.

Received: September 9, 2009. Revised: 1st, September 29, 2009; 2nd, October 14, 2009. Accepted: December 17, 2009.

Corresponding author: Dae Geun Jeon, M.D., Department of Anesthesiology and Pain Medicine, College of Medicine, Dankook University, San 16-5, Anseo-dong, Cheonan 330-715, Korea. Tel: 82-41-550-6819, Fax: 82-41-551-9330, E-mail: timepain@hanmail.net

The present study was conducted by the research fund of Dankook University in 2008.

(ㄷ) This is an open-access article distributed under the terms of the Creative Commons Attribution Non-Commercial License (http:// creativecommons.org/licenses/by-nc/3.0/), which permits unrestricted non-commercial use, distribution, and reproduction in any medium, provided the original work is properly cited. 


\section{Introduction}

Supraclavicular brachial plexus block has many advantages. The brachial plexus is highly compact in the supraclavicular region. Therefore, a blockade achieves acute onset and excellent anesthesia of the entire arm and hand with a relatively small volume of local anesthetics. In addition, the arm doesn't need to be abducted as in an axillary brachial plexus block $[1,2]$.

The classical approaches for a supraclavicular block are all blind techniques that depend on sensory paresthesia or a nervestimulated muscle contraction. Sometimes, multiple needle attempts are needed to elicit sensory paresthesia or a muscle twitch response, which can result in pain and complications such as neurological injury and pneumothorax $[3,4]$.

Ultrasound-guided brachial plexus block can increase the success rates and reduce the incidence of complications [5]. However it is very difficult to locate the structures such as subclavian artery and brachial plexus clusters in some people.

Therefore, the aims of this study were to obtain reliable clinical data on ultrasound-guidedsupraclavicular block, demonstrate the higher success rate and fewer complications, and design an injection method for the patients whose brachial plexus can not be located.

\section{Materials and Methods}

After gaining protocol approval by our institutional review board, and informed consent from the patients, 105 patients with ASA grade 1 and 2 who were to undergo elective surgery of the forearm and hand were enrolled in this study (Table 1).

No patients received premedication. Immediately after arriving in the operating room, standard monitoring equipments (EKG, non-invasive blood pressure measurement, pulse oximetry) were attached to all patients before performing the supraclavicular brachial plexus block.

For the supraclavicular plexus block, the patients were placed in the supine position with their heads turned in the direction opposite the limbs to be anesthetized. The arms to be blocked were placed in an anatomical neutral position, along the body. Subsequently the probe (linear type, $12 \mathrm{MHz}$ ) of the ultrasound

Table 1. Demographic Characteristics of the Patients

\begin{tabular}{lccc}
\hline & Group A & Group B & $\begin{array}{c}\text { Total of } \\
\text { Group A and B }\end{array}$ \\
\hline Sex (M/F) & $58 / 34$ & $8 / 5$ & $66 / 39$ \\
Age (yr) & $40.4 \pm 15.5$ & $36.3 \pm 15.2$ & $39.9 \pm 15.4$ \\
Height (cm) & $165.7 \pm 8.8$ & $165.0 \pm 7.6$ & $165.6 \pm 8.6$ \\
Weight (kg) & $63.3 \pm 9.8$ & $67.9 \pm 9.2$ & $63.9 \pm 9.8$ \\
\hline
\end{tabular}

The values are reported as the mean \pm standard deviation. Group A: patients with a visible brachial plexus, Group B: patients whose brachial plexus could not be located. equipment (Vivid ${ }^{\circledR}{ }^{\circledR}$, GE Yokogawa Medical Systems Ltd., Tokyo, Japan) wrapped within a rubber glove was placed on the supraclavicular fossa to locate the subclavian artery and brachial plexus cluster. After local anesthetic infiltration, a 50 mm $22 \mathrm{G}$ insulated short beveled stimulation needle (Stimuplex ${ }^{\circledR}$ A, B. Braun Melsungen AG, Germany) was inserted toward the brachial plexus cluster from the lateral to medial in the long axis of the ultrasound beam after locating the subclavian artery and brachial plexus cluster.

Once the needle tip reached the brachial plexus cluster on the ultrasound image, 1 to $2 \mathrm{ml}$ of $1 \%$ mepivacaine was injected. If a local anesthetic was distributed around the brachial plexus cluster or the nerve was pushed to the periphery, the remaining local anesthetic (total $40 \mathrm{ml}$ ) was then injected (Fig. 1, 2).

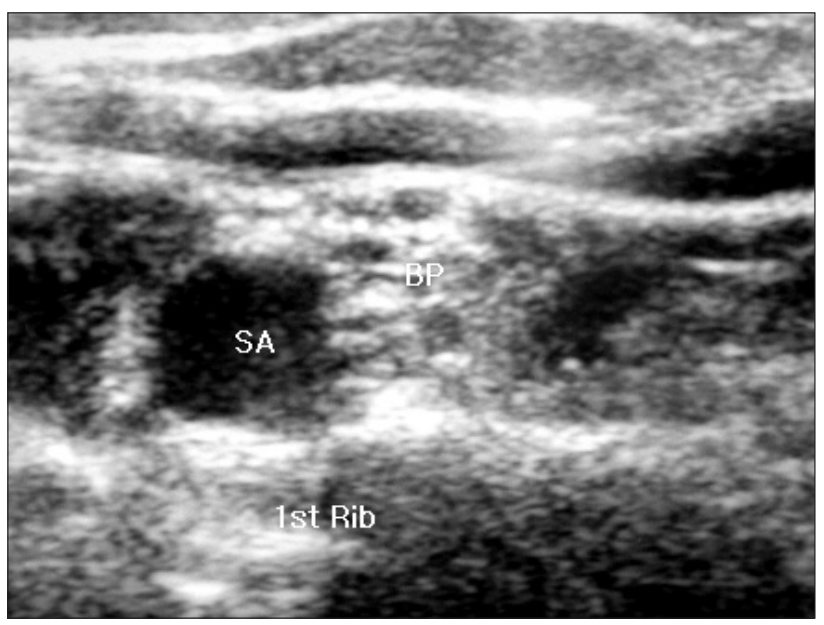

Fig. 1. The ultrasound image of the supraclavicular brachial plexus at the level of the first rib. The subclavian artery and the trunks of the brachial plexus can be seen. SA: subclavian artery, BP: brachial plexus.

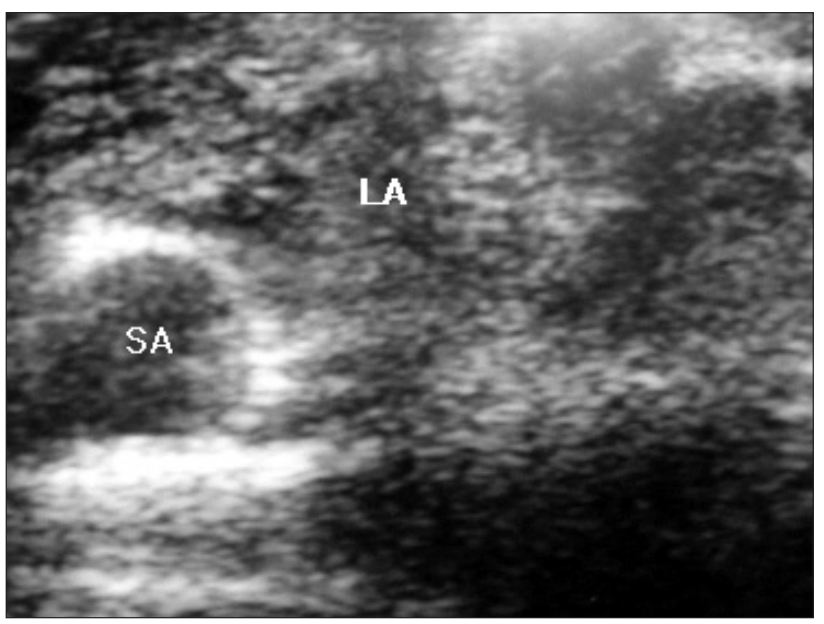

Fig. 2. The ultrasound image of the supraclavicular brachial plexus after the local anesthetic injection at the level of the first rib. SA: subclavian artery, LA: local anesthetic distribution. 
The needle tip was repositioned if the local anesthetic spreaded inappropriately. Sometimes the patients complained of paresthesia. When this occurred, the needle was withdrawn and repositioned until the patients did not complain it. During the study, some cases with a brachial plexus that was vague or not visible on the ultrasound image were found (Fig. 3). Thus the patients were divided into two groups according to the visibility of the brachial plexus cluster on the ultrasound image. Group A consisted of patients in whom the brachial plexus cluster could be visualized on the ultrasound image while the Group B consisted of patients in whom the brachial plexus cluster was vague or not visualized on the ultrasound image.

In the case of Group B, the local anesthetic was injected at the distance of its diameter $(25 \mathrm{ml})$ from the subclavian artery and superior lateral $(15 \mathrm{ml})$ to the subclavian artery according to the normal anatomy (Fig. 3).

From 1 minute to 30 minutes after the blocks, the other anesthesiologist tested the extent of the sensory block at 1 minute intervals. The onset of the sensory block was evaluated using a pinprick test with a $26 \mathrm{G}$ needle. The following five nerves were tested: 1) musculocutaneous nerve (lateral side of the forearm); 2) radial nerve (dorsum of the hand over the 2 nd metacarpophalangeal joint); 3) median nerve (medial thenar eminence); 4) ulnar nerve (little finger); 5) median cutaneous nerve (medial side of the forearm). A successful block was defined as complete sensory block of the above 5 terminal nerves assessed within 30 minutes of the local anesthetic injection and operability.

All patients were checked for Horner's syndrome, voice changes, and dyspnea or chest discomfort, and they were sedated with midazolam or propofol after the tests. Postoperative chest

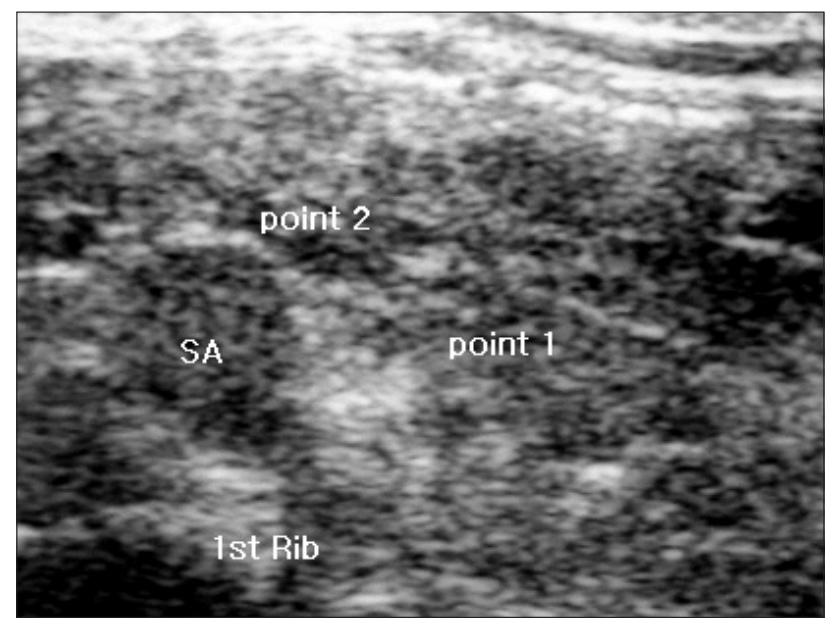

Fig. 3. Ultrasound image of the supraclavicular brachial plexus at the level of the first rib. The wall of subclavian artery is vague and the brachial plexus can not be seen well. SA: subclavian artery, Point 1: the first injection site, Point 2: the second injection site.
X-rays were then obtained to check for hemi-diaphragmatic paralysis and pneumothorax .

The data was analyzed using a Student t-test, Mann-Whitney $\mathrm{U}$ test and Chi-square test. A P value $<0.05$ was considered significant.

\section{Results}

The overall success rate of the block was $97.1 \%(102 / 105$ patients). The success rate in Group A (98.9\%, 91/92 patients) was higher than that in Group B $(84.6 \%, 11 / 13$ patients $)(\mathrm{P}<$ $0.05)$. However 3 failures could be operated on under sedation with the iv midazolam and propofol infusion.

The overall time to onset was $13.8 \pm 5.5 \mathrm{~min}$. The time to onset in Group B (23.1 $\pm 5.1 \mathrm{~min})$ was longer than that in Group A (12.6 $\pm 4.4 \mathrm{~min})(\mathrm{P}<0.05)$ (Table 2).

Dyspnea or chest discomfort was encountered in $8.7 \%$ and $15.4 \%$ of Group A and B respectively, but differences were not significant. Hemidiaphragmatic paralysis was encountered in $36.6 \%$ and $30.8 \%$ of Group A and B, respectively, but the differences were not significant. A recurrent laryngeal nerve block was observed in $2.2 \%$ of Group A. But the differences were not significant. There were no differences in the other side effects (Table 3).

Table 2. Time to Onset of Each 5 Terminal Nerve

\begin{tabular}{lrcc}
\hline \multirow{2}{*}{ Sensory distribution } & \multicolumn{3}{c}{ Time to onset (minutes) } \\
\cline { 2 - 4 } & Group A & Group B & $\begin{array}{c}\text { Average of } \\
\text { Group A and B }\end{array}$ \\
\hline Musculocutaneous nerve & $8.0 \pm 2.8$ & $10.6 \pm 3.0^{*}$ & $8.3 \pm 2.9$ \\
Radial nerve & $7.4 \pm 3.1$ & $11.6 \pm 7.2$ & $7.8 \pm 3.9$ \\
Ulna nerve & $11.0 \pm 5.2$ & $22.0 \pm 5.6^{*}$ & $12.2 \pm 6.2$ \\
Median nerve & $9.0 \pm 4.1$ & $14.4 \pm 4.5^{*}$ & $9.5 \pm 4.5$ \\
Median cutaneous nerve & $8.3 \pm 4.3$ & $15.4 \pm 6.5^{*}$ & $9.1 \pm 5.1$ \\
Average of all nerves & $12.6 \pm 4.4$ & $23.1 \pm 5.1^{*}$ & $13.8 \pm 5.5$ \\
\hline
\end{tabular}

The values are reported as the mean \pm standard deviation. Group A: patients with a visible brachial plexus, Group B: patients whose brachial plexus could not be located. ${ }^{*} \mathrm{P}<0.05$ compared with Group A.

Table 3. Incidence of Side Effects during Block

\begin{tabular}{lccc}
\hline & $\begin{array}{c}\text { Group A } \\
(\%)\end{array}$ & $\begin{array}{c}\text { Group B } \\
(\%)\end{array}$ & $\begin{array}{c}\text { Total of } \\
\text { Group A and B (\%) }\end{array}$ \\
\hline $\begin{array}{l}\text { Horner's syndrome } \\
\begin{array}{l}\text { Dyspnea or chest } \\
\text { discomfort }\end{array}\end{array}$ & 68.5 & 69.2 & 68.6 \\
$\begin{array}{l}\text { Recurrent laryngeal } \\
\text { nerve block }\end{array}$ & 2.2 & 15.4 & 9.5 \\
$\begin{array}{l}\text { Hemidiaphragmatic } \\
\text { paralysis }\end{array}$ & 32.6 & 30.8 & 1.9 \\
$\begin{array}{l}\text { Pneumothorax } \\
\text { Theum }\end{array}$ & 0 & 0 & 32.4
\end{tabular}

The values are reported as the mean \pm standard deviation. Group A: patients with a visible brachial plexus, Group B: patients whose brachial plexus could not be located. 


\section{Discussion}

The reported success rates in ultrasound-guided supraclavicular block varies between $78 \%$ and 95\% [6-8]. However our overall success rate was $97.1 \%$ (102/105 patients), which is comparable to other studies using a combination of ultrasound and nerve stimulation techniques.

The reason why our success rate was higher is that this study used a larger local anesthetic volume $(40 \mathrm{ml})$, multiple injections and a single well-trained operator performed the blocks, whereas the other studies used a lower local anesthetic volume down to $20 \mathrm{ml}$ and many operators including residents.

Sensory paresthesia or motor response is believed to be a definitive sign that the needle is touching the nerve directly. However after the introduction of ultrasound, an operator can see the precise needle location without eliciting paresthesia or a motor response.

Therefore, it is believed that a paresthesia or motor response is not the gold standard for a correct needle location for a supraclavicular brahcial plexus block. This concept is not new. Beach et al. [9] demonstrated that the use of a nerve stimulator did not improve the efficacy of ultrasound-guided supraclavicular blocks, which was also observed in this study. This suggests that a paresthesia or a motor response is not the gold standard for a successful block.

13 cases $(12.4 \%)$ with brachial plexus that was vague or not visible on the ultrasound image were encountered during the study. In these cases, local anesthetics were injected according to the normal anatomy. It was assumed that local anesthetics injected lateral or superior lateral to the subclavian artery could reach the brachial plexus because the location of the brachial plexus was normally located lateral or superior lateral to the subclavian artery. The success rate in Group B was 84.6\% (11/13 patients), which was lower than that in Group A (98.9\%, 91/92 patients), the onset of the block was also slower than that of the patients whose brachial plexus was visible. This means that the local anesthetics injected took more time to reach the brachial plexus in those patients whose brachial plexus could not be located. However Chin et al. [10] reported a case of an anomalous brachial plexus anatomy. The patient's superior trunk of the brachial plexus was medial to the subclavian artery at the level of the first rib. In the light of their report, the method performed in the present study might have the problem in the patients with anomalous brachial plexus. It is believed that a reduced block can occur in the patients with an anomalous brachial plexus if the local anesthetics are injected by this method. However the 2 failures in Group B could be operated on under sedation.

A nerve stimulator was not used in this study. It is believed that the success rate could be higher in even patients whose brachial plexus can not be located if a nerve stimulator had been used during the ultrasound-guided supraclavicular block in Group B.

Athough a supraclavicular block has many advantages, it can have important or fatal complications, which include dyspnea and pneumothorax [1,2]. Dyspnea occurs from diaphragmatic paralysis or pneumothorax. However the dyspnea caused by hemidiaphragmatic paralysis is not clinically important in patients without respiratory diseases such as chronic obstructive disease or asthma. However dyspnea with pneumothorax can be fatal.

There is a $100 \%$ incidence of hemidiaphragmatic paralysis accompanied with a $25 \%$ decrease in the forced vital capacity (FVC) when an interscalene block is performed [11]. However, there is only a 30 to $50 \%$ incidence of hemidiaphragmatic paralysis with no decrease in the FVC when a supraclavicular block is performed $[12,13]$. Therefore dyspnea caused by diaphragmatic paralysis in supraclavicular block is not clinically important.

In this study, $9.5 \%$ of patients complained of dyspnea or chest discomfort and $32.4 \%$ patients showed hemidiaphragmatic paralysis on the post operative chest X-rays. This is similar to the incidence of hemidiaphragmatic paralysis reported by Farrar et al. [12]. Their study included both a quantitative pulmonary function test and chest X-ray. However, quantitative pulmonary function test with spirometer was not performed in this study. Therefore the dyspnea or chest discomfort that the patients complained of could not be tested objectively.

The dyspnea caused by pneumothorax can be fatal after a supraclavicular block. Therefore some anesthesiologists avoid a supraclavicular block for fear of pneumothorax. The published incidence of pneumothorax varies from $0.5 \%$ to $6 \%$ in the classical supraclavicular approach with paresthesia for nerve localization $[1,2]$. Ultrasound guidance is believed to decrease the incidence of pneumothrax during a supraclavicular brachial plexus block [5]. Indeed no pneumothorax has been reported until now. Unlike conventional techniques, ultrasound can show the size, depth, and precise location of the brachial plexus and its adjacent structures including the first rib, pleura and movement of the needle. Therefore, real time ultrasound imaging can help avoid pneumothorax.

In conclusions, a supraclavicular block using ultrasound is a useful method for regional anesthesia. An almost $100 \%$ block can be obtained without eliciting sensory paresthesia or a motor response. It can also help avoid pneumothorax, which is an important complication of a supraclavicular block. This study also showed a successful block without gaining a precise image of brachial plexus. It is expected that the use of supraclavicular brachial plexus block will become more widespread in the future. 


\section{References}

1. Fleisher LA, Johns RA, Savarese JJ, Wiener-Kronish JP, Young WL. Miller's Anesthesia. 6th ed. Philadelphia, Churchill-Livingstone. 2005, p 1690.

2. Morgan GE, Mikhail MS, Murray MJ. Clinical Anesthesiology. 4th ed. New York, Lange Medical Books/McGraw-Hill Medical Publishing Division. 2006, pp 332-3.

3. Fanelli G, Casati A, Garancini P, Torri G. Nerve stimulator and multiple injection technique for upper and lower limb blockade: failure rate, patient acceptance, and neurologic complications. Study Group on Regional Anesthesia. Anesth Analg 1999; 88: 84752.

4. Choyce A, Chan V, Middleton W, Knight P, Peng P, McCartney C. What is the relationship between paresthesia and nerve stimulation for axillary brachial plexus block? Reg Anesth Pain Med 2001; 26 : 100-4.

5. Kapral S, Krafft P, Eibenberger K. Ultrasound-guided supraclavicular approach for regional anesthesia of the brachial plexus. Anesth Analg 1994; 78: 507-13.

6. Williams SR, Chouinard P, Arcand G, Harris P, Ruel M, Boudreault $\mathrm{D}$, et al. Ultrasound guidance speeds execution and improves the quality of supraclavicular block. Anesth Analg 2003; 97: 1518-23.

7. Chan VW, Perlas A, Raw R, Odukoya O. Ultrasound-guided supraclavicular brachial plexus block. Anesth Analg 2003; 97: 15147.

8. Tsui BC, Doyle K, Chu K, Pillay J, Dillane D. Case series: ultrasoundguided supraclavicular block using a curvilinear probe in 104 daycase hand surgery patients. Can J Anaesth 2009; 56: 46-51.

9. Beach ML, Sites BD, Gallagher JD. Use of a nerve stimulator does not improve the efficacy of ultrasound-guided supraclavicular nerve blocks. J Clin Anesth 2006; 18: 580-4.

10. Chin KJ, Niazi A, Chan V. Anomalous brachial plexus anatomy in the supraclavicular region detected by ultrasound. Anesth Analg 2008; 107: 729-30.

11. Urmey WF, Talts KH, Sharrock NE. One hundred percent incidence of hemidiaphragmatic paresis associated with interscalene brachial plexus anesthesia as diagnosed by ultrasonography. Anesth Analg 1991; 72: 498-503.

12. Farrar MD, Scheybani M, Nolte H. Upper extremity block, effectiveness and complications. Reg Anesth 1981; 6: 133-4.

13. Neal JM, Moore JM, Kopacz DJ, Liu SS, Kramer DJ, Plorde JJ. Quantitative analysis of respiratory, motor, and sensory function after supraclavicular block. Anesth Analg 1998; 86: 1239-44. 